\title{
REVIEW OF LASER DEPOSITED SUPERALLOYS USING POWDER AS AN ADDITIVE
}

\author{
Andreas Segerstark ${ }^{1}$, Joel Andersson ${ }^{1,2,3}$, Lars-Erik Svensson ${ }^{1}$ \\ ${ }^{1}$ Department of Engineering Science, University West, Trollhättan, SE-461 86, Sweden \\ ${ }^{2}$ GKN Aerospace Engine Systems, Trollhättan, SE-461 81, Sweden \\ ${ }^{3}$ Department of Materials and Manufacturing Technology, Chalmers University of Technology, \\ Gothenburg, SE-412 96, Sweden
}

Keywords: Laser, Deposition, Additive manufacturing, Powder, Nickel, Nickel-iron, Superalloy

\begin{abstract}
In this paper laser metal deposition (LMD) with blown powder was reviewed with respect to the material behavior of nickel and nickel-iron based superalloys. The key benefits of LMD are claimed to be increased design freedom of components as well as reduced environmental impact since it enables near net shape manufacturing. This review considers the LMD processing parameters such as laser power, powder feed rate, spot size, standoff distance, and traverse speed, together with aspects related to the powder e.g. morphology, porosity, inclusion and satellite content. Special emphasis was put on how these parameters affect the deposit and substrate in terms of cracking, porosity, inclusions, phase transformations, and other material related phenomena. A characteristic microstructure of LMD deposited superalloys has a columnar dendrite growth in the vertical build up direction. The grain growth can however be manipulated, making it more equiaxed by, for instance, altering process parameters and/or scanning path. Residual stresses in LMD samples are unevenly distributed and large residual tensile stresses can be found at the surface of the deposit while large compressive stresses are located close to the substrate in the core of the deposit. One of the most important parameter is considered to be the specific energy input which largely influences the melt pool during deposition which in turn can be related to the microstructure, residual stress and, process related defects such as porosity, cracking, lack of fusion and, dilution.
\end{abstract}

\section{Introduction}

Additive manufacturing (AM), is a collective name for production methods which have the capability of producing 3-D geometries, layer by layer, close to net shape without the use of any dies. AM has drawn much attention during the last decade as a field of research especially in the aerospace, nuclear and biomedical industry. The increased interest of AM is shown by the increasing trend of published papers during the last decade, which is shown in Figure 1. The development of AM has led to a number of manufacturing methods of which the ones' used for processing metal will be mentioned briefly in this paper. These include: laminated object manufacturing [1], powder-bed technologies [2, 3], and deposition technologies [4]. Depending on the AM method, the forms of feedstock material differ between sheet, powder and wire. The feedstock material is either bonded, sintered, fused or cut in order to produce the final component. The energy source which is used to process the material also differs in between the different AM methods. The possible energy sources include laser, electron beam, electric arc, 
and water jet. Figure 2 below shows an overview of the AM methods and the correlation in between the method,

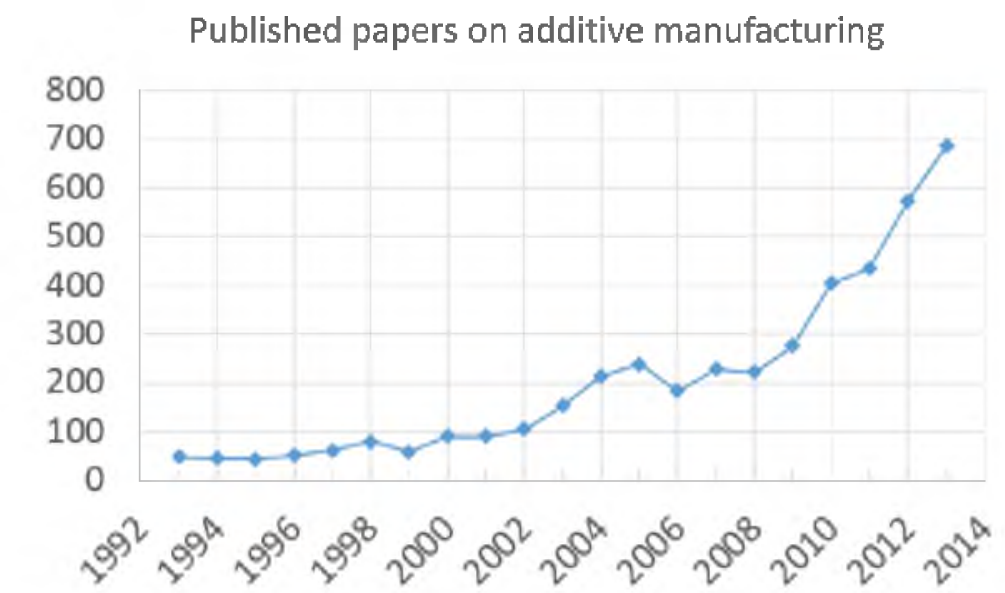

Figure 1 Published papers in AM during the period 1993-2013 [5].

feedstock, processing, and energy source. As highlighted in Figure 2, this review was focused on laser metal deposition (LMD) using blown powder to additively deposit nickel (Ni) and nickeliron (Ni-Fe) based superalloys. Additionally, there are many different powder production methods which yield varying powder characteristics and performances. The most common powders covered by the literature are gas atomized (GA) powder and plasma rotary electrode process powder (PREP) which will be covered in this paper.

Laser metal deposition with powder

Deposition of material directly on a metal surface using laser is known by many different names such as: laser metal deposition (LMD), direct metal deposition or laser direct metal deposition [6-10], laser engineered net shaping [11], laser consolidation [12], laser rapid manufacturing [13] and more. LMD is a novel method of additive manufacturing which uses a multi-axis CNC machine or robot to guide the laser beam and powder nozzle over the deposition surface. The component is built by depositing adjacent beads layer by layer until the component is completed, as illustrated in Figure 3. There are some different nozzle types which provide the powder either off-axis though an external nozzle or coaxially where the powder is provided axisymmetrical to the laser beam.

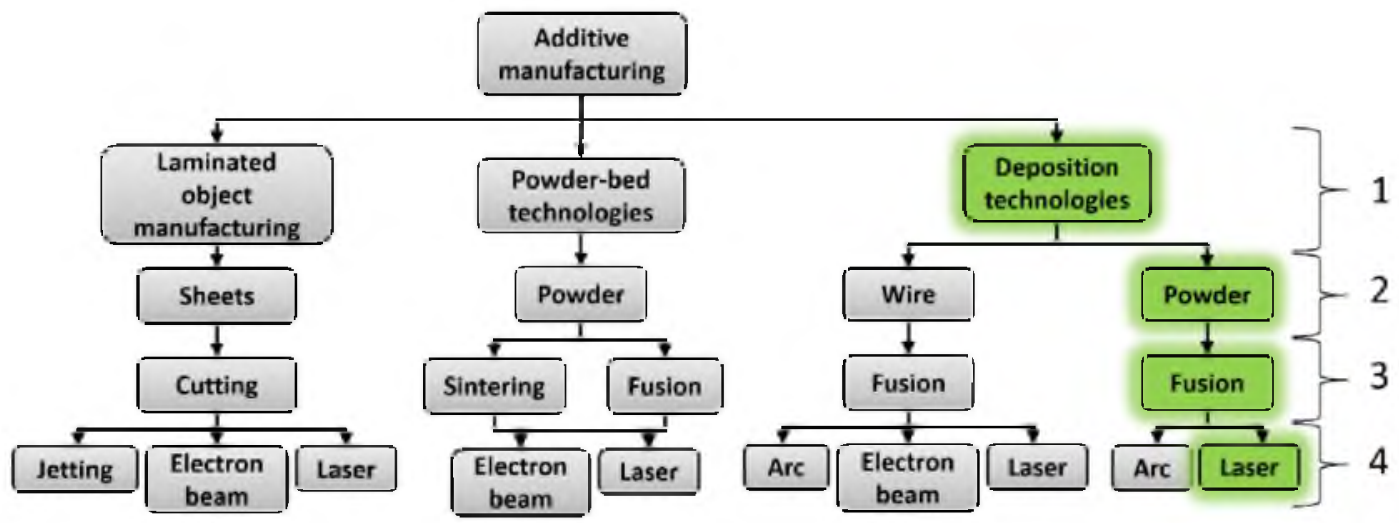

Figure 2. Process map over additive manufacturing methods. The arrows show the combinations on what each AM methods can be composed of. The highlighted windows composes the LMD method. The schematic is further on divided into four categories which are: 1 , the different AM- 
methods, 2. the different additive materials, 3 . the different processing methods. 4 . The different energy sources. Modified from [14].

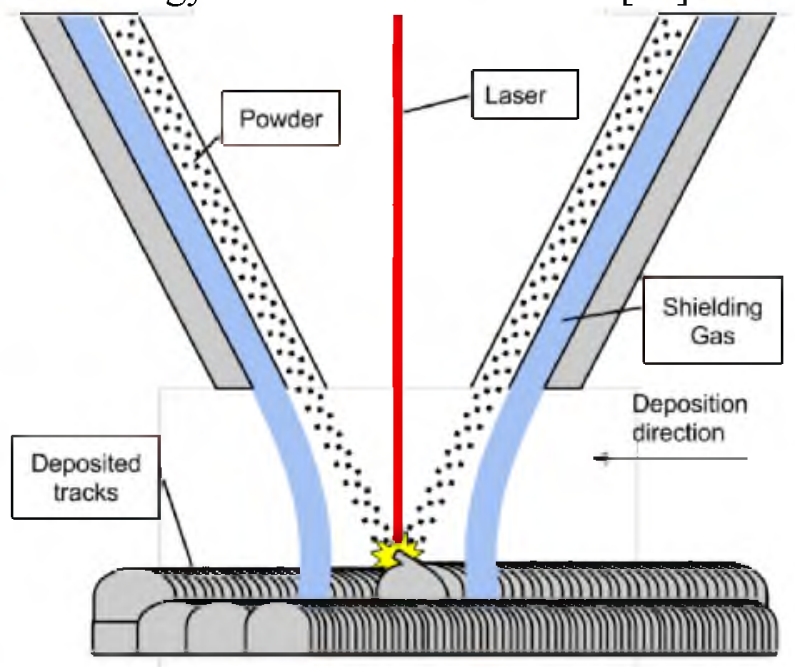

Figure 3. A cross section of a coaxial Laser Metal Deposition (LMD) nozzle. The powder is carried by a gas, typically argon or helium. Furthermore, the melt pool is shielded by an inert gas such as argon or helium.

\section{Material characteristics and process parameters}

Nickel based superalloys are highly utilized in the aero industry and more than $50 \%$ of an aero engine's weight consist of superalloys. The chemical composition of nickel based superalloys consists of about 10-15 elements, beyond nickel, which all contribute to the performance of the material. These elements include: aluminum, boron, carbon, chromium, cobalt, hafnium, iron, magnesium, manganese, molybdenum, niobium, rhenium, tantalum, titanium, tungsten, and zirconium [15]. A broad range of superalloys has been evaluated for LMD including Alloy-625 [13, 16-20], Alloy-718 [6, 21-31], Alloy-738 [12, 32], CMSX4 [33-35], René41 [36, 37] and Waspaloy $[10,38]$.

There are some parameters of particular importance to LMD, as listed in Table 1 , to have a controlled deposition. The outcome of the deposit in terms of surface finish, microstructure and mechanical properties is to a high degree governed by these process parameters [13, 39, 40]. Figure 4 shows a schematic overview of the process parameters and powder characteristics effect on the deposition process characteristics which consequently affects the material characteristics in the finished component.

Table 1. The key process parameters in the LMD process [7] [41] [42].

\begin{tabular}{|c|c|c|}
\hline Parameter & Unit & Description \\
\hline Laser power & $\mathrm{W}$ & $\begin{array}{c}\text { The power of the laser beam which fuses the powder } \\
\text { with the substrate }\end{array}$ \\
$\begin{array}{c}\text { Traverse speed } \\
\text { Laser spot size }\end{array}$ & $\begin{array}{c}\mathrm{mm} / \mathrm{s} \\
\mathrm{mm}\end{array}$ & $\begin{array}{c}\text { Travel speed of the laser and powder } \\
\text { The diameter of the laser beam }\end{array}$ \\
Laser standoff distance & $\mathrm{mm}$ & $\begin{array}{c}\text { The distance between deposition surface and laser } \\
\text { focus }\end{array}$ \\
Powder standoff distance & $\mathrm{mm}$ & $\begin{array}{c}\text { The distance between powder focus and deposition } \\
\text { surface }\end{array}$ \\
Powder feeding rate & $\mathrm{g} / \mathrm{s}$ & The amount of powder which is fed into the melt pool \\
\hline
\end{tabular}




\begin{tabular}{|c|c|c|}
\hline $\begin{array}{c}\text { Shield and carrier gas flow } \\
\text { rate }\end{array}$ & $1 /$ min & The flow rate of the shielding and carrier gas \\
\hline
\end{tabular}

Two of the most important parameters in LMD are specific energy, which is the energy density at the surface of the deposition, and the line mass which is the mass of material, which is available for deposition per unit length of track. Specific energy and line mass are calculated with Equation (1) and Equation (2) respectively [43].

$$
\begin{gathered}
\text { Specific energy }=\frac{P_{L}}{D_{L^{*}}} \\
\text { Line mass }=\frac{Q_{p}}{V}
\end{gathered}
$$

where, $\mathrm{P}_{\mathrm{L}}$ is the laser power in watt, $\mathrm{D}_{\mathrm{L}}$ is the laser diameter in $\mathrm{mm}, \mathrm{V}$ is the traverse speed in $\mathrm{mm} / \mathrm{s}$ and $Q_{p}$ is the powder flow rate in $\mathrm{g} / \mathrm{s}$.

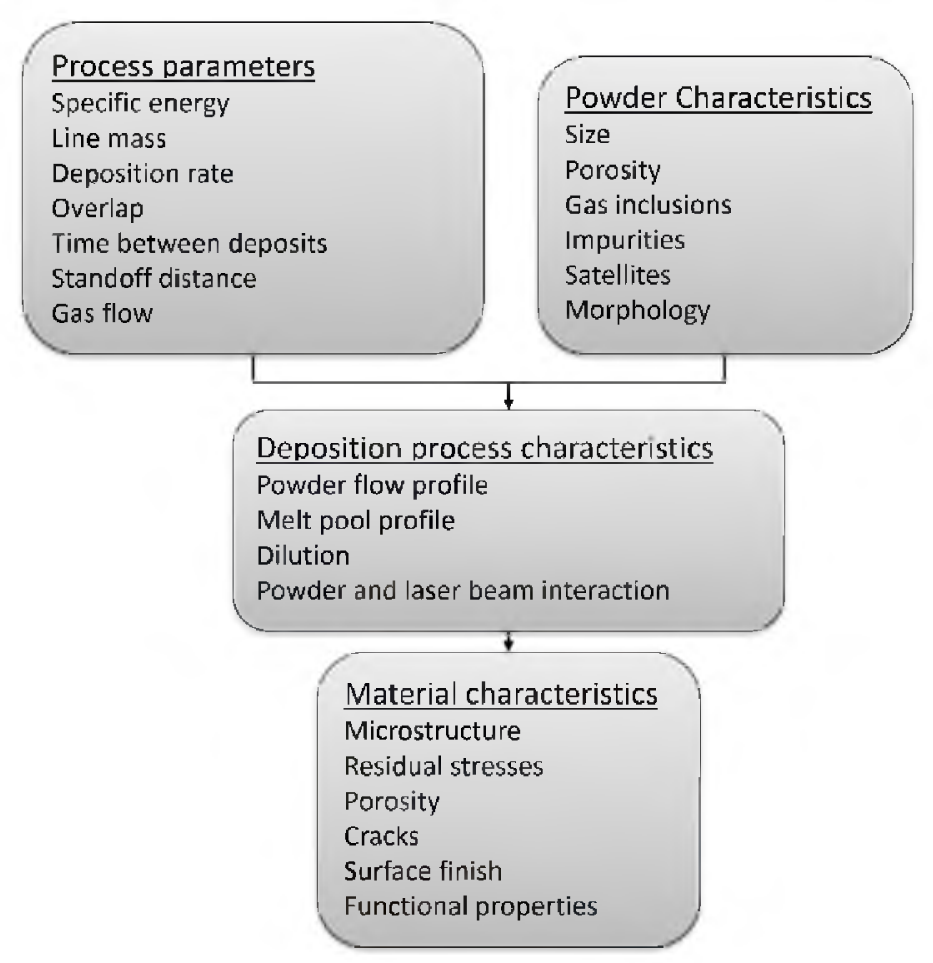

Figure 4. Schematic overview of parameters that are found to be of significant importance to the LMD process. Modified from [44].

Bead geometry

The height of a single-deposit track can be connected to powder feed rate, scanning velocity, laser power, laser spot diameter, powder focus and laser focus. The height of a single-deposition track is an important forming characteristic which partly determines the forming dimension precision in the vertical direction and the fabrication efficiency. Powder feed rate and scanning 
speed greatly affects the deposit height since these determines the amount of powder that are sprayed into the deposited track and the amount of energy that is absorbed into the melt pool, respectively. The effect of the laser power and spot diameter are linked to the power density (laser power to spot area). Low laser power leads to insufficient powder adhesion, bonding defects and un-melted powder residues in the deposit. However, too high laser power leads to overheating of the powder and oxidation in the deposit. It is therefore important to control the power density carefully. As with the height of a deposit track, the width is affected by the powder feeding rate, scanning speed, laser power and spot diameter. Increasing the powder feed rate leads to wider deposits. Higher scanning velocity means less material in the melt pool which leads to narrower tracks. Higher laser power density creates a wider deposition track [45]. The ratio between the width and the height of a single deposit track is an important design factor from which the process parameters quickly can be assessed. A deposit track that is too flat and wide leads to a large amount of remelting of the substrate which can lead to dilution, see Figure 5 (a). Additionally, the forming precision is degraded due to the excessive melting, especially for thin walled structures and smaller components. Excessive heat input is also probable when this geometry is achieved which can lead to excessive oxidation, cracking caused by residual stresses, a large heat affected zone in the substrate and thermal distortion [44]. Another geometry, (b.) characteristically entails porosities and are achieved using a low specific energy together with a low line mass. The desired geometry can be seen in (c.).

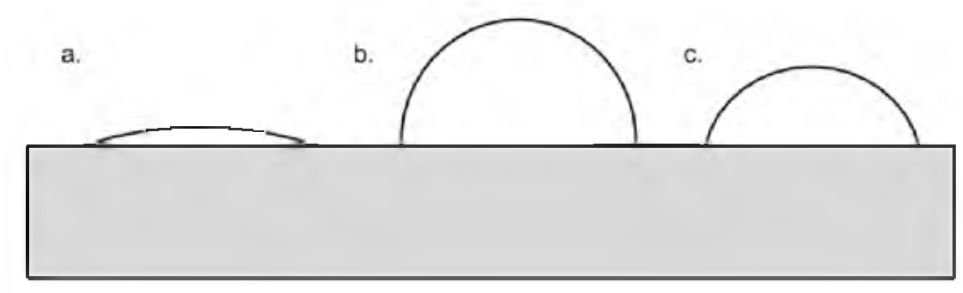

Figure 5. Three different deposit bead geometries. (a.) is a flat wide deposit which characterizes a large heat input. (b.) characterizes lesser heat input which yields a porous deposit and (c) is the target geometry.

A theoretically optimum sidestep distance and overlapping rate, from a forming precision point of view, can be determined from the width and height of the deposited beads, assuming that the beads curvature is the same as the upper section of a circle where the height $\leq \frac{\text { width }}{2}$, see Figure $6[45]$. 


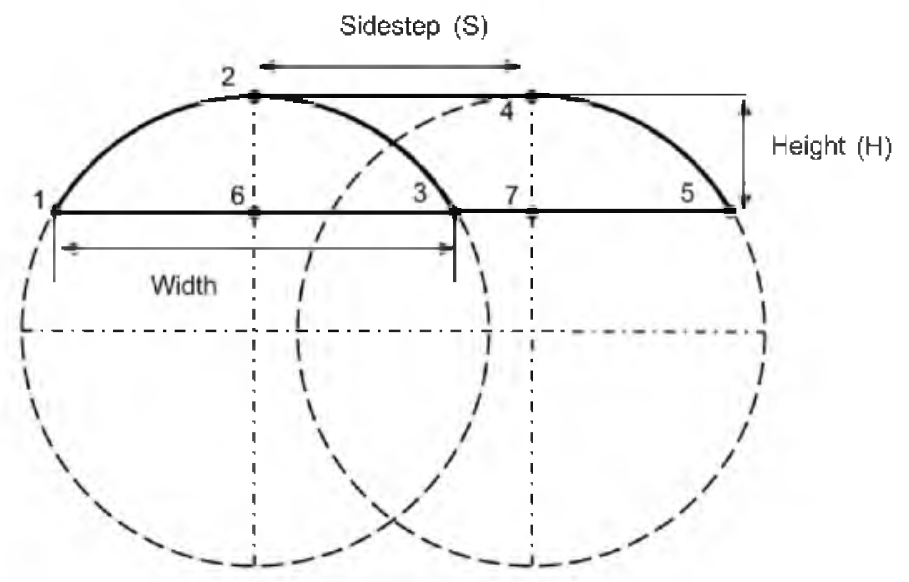

Figure 6. A schematic of the cross-section of two adjacent deposit tracks. Modified from [45].

The theoretical optimum sidestep distance is then calculated from equations (3), (4) and (5).

$$
\begin{gathered}
A_{123}=A_{2453}=A_{2476}=H * S \\
A_{123}=\left(\frac{\left(\frac{W}{2}\right)^{2}+H^{2}}{2 H}\right)^{2} \arcsin \frac{2\left(\frac{W}{2}\right) H}{\left(\frac{W}{2}\right)^{2}+H^{2}}-\left(\frac{W}{2}\right) \frac{\left(\frac{W}{2}\right)^{2}-H^{2}}{2 H} \\
S=\frac{A_{123}}{H}=\frac{\left(\left(\frac{\left(\frac{W}{2}\right)^{2}+H^{2}}{2 H}\right)^{2} \arcsin \frac{2\left(\frac{W}{2}\right) H}{\left(\frac{W}{2}\right)^{2}+H^{2}}-\left(\frac{W}{2}\right)^{\left.\frac{\left(\frac{W}{2}\right)^{2}-H^{2}}{2 H}\right)}\right.}{H}
\end{gathered}
$$

Where $\mathrm{A}$ is the cross-sectional area of the section specified by the numbered junctions in Figure $6, \mathrm{~W}$ is the width of a single deposit track, $\mathrm{H}$ is the height of a single deposit track, and $\mathrm{S}$ is the optimal side step distance. The overlap rate is then calculated from equation (6).

$$
n_{c}=\frac{(W-S)}{W}
$$

where $n_{c}$ is the overlap rate.

The microstructure of deposited superallovs

The microstructure of a superalloy is composed of a face centered cubic (fcc) $\gamma$-matrix in which a number of secondary phases, namely $\gamma^{\prime}, \gamma^{\prime}, \delta, \eta$ or $\sigma$ could be dispersed. The location, morphology, size, and composition of the secondary phases highly affect the performance of superalloys. The main strengthening mechanism in nickel-based superalloys is precipitation hardening where $\gamma^{\prime}$ and/or $\gamma^{\prime}$ are the primary contributors. Aluminum, titanium are added in a controlled fashion in order to precipitate $\gamma^{\prime}-\mathrm{Ni}_{3}(\mathrm{Ti}, \mathrm{Al})$ from the $\gamma$ matrix. Niobium is added to precipitate $\gamma$ ' $-\mathrm{Ni}_{3} \mathrm{Nb}$ from the matrix. Both $\gamma$ ' and $\gamma$ ' are metastable and may transform to hexagonal close packed $\eta$ - and orthorhombic $\delta$-phase, respectively, after prolonged exposure to 
elevated temperatures. Another important strengthening mechanism is the formation of carbides. The carbides precipitate on the grain boundaries and increase the high temperature creep resistance by moving the intergranular creep process to a transgranular creep process. Preferably the carbides should be small, globular and non-cohesive in order to achieve maximum strengthening of the grain boundaries. The most commonly found carbides in Ni and Ni-Fe based superalloys are $\mathrm{MC}$ and $\mathrm{M}_{6} \mathrm{C}$ carbides where the $\mathrm{M}$ is composed of molybdenum, niobium, tungsten, chromium and/or titanium. However, these carbides are metastable and may transform into $\mathrm{M}_{23} \mathrm{C}_{6}$ during prolonged exposure to elevated temperatures. $\mathrm{M}_{23} \mathrm{C}_{6}$ carbides are cohesive with the matrix, but inherently brittle in nature. When $\mathrm{M}_{23} \mathrm{C}_{6}$ precipitates along the grain boundaries it provides a path of lower resistance for crack propagation. Additionally, $\mathrm{M}_{23} \mathrm{C}_{6}$ carbides have a tendency to agglomerate and thereby forming few and large carbides which can acts as crack initiation sites [15].

A columnar dendrite growth in the vertical build-up direction is characteristic for LMD deposited samples. During solidification of melt pools created during the LMD process the unmelted substrate acts as a heat sink which aids Directional Solidification (DS). It is possible to maintain epitaxial, columnar and single crystal (SX) growth in the deposit if certain boundary conditions are controlled. The columnar to equiaxed transformation need to be avoided and sufficient remelting of the substrate needs to be ensured [34]. The two most important parameters that govern the solidification mode are the temperature gradient and the solidification velocity. These parameters can be manipulated in LMD by controlling the laser power, laser spot size and traverse speed. By keeping the laser power low, a larger temperature gradient can be achieved which can results in a more dominant columnar grain growth mode. Secondly, a smaller laser beam diameter has a positive effect on the columnar grain growth by changing the melt-pool and ensuring sufficient remelting. Thirdly, a low traverse speed increases the probability of a columnar grain growth by lowering the solidification velocity $[34,35,46]$. The macro- and microstructure of LMD deposited superalloys have been evaluated by various researchers and is summarized below.

- Gäumann et al. 2001 [34] did numerical and parametrical studies on CMSX-4 to develop process parameter maps which help to tailor the microstructure in terms of grain morphology and grain growth orientation by altering the laser power, scanning speed and laser spot diameter.

- W. Liu et al. [47] developed a numerical model to predict the crystalline growth orientation in a laser melted surface by estimating temperature field and fluid flow in the weld pool. The model showed fairly good agreement with experimental results.

- C. Jun et al. [22] reported that the columnar grains in a deposit with $20 \%$ overlap were wider and longer than those in the deposits which had 30,40 or $50 \%$ overlap. The grain growth direction of the columnar grains for the as-deposited parts were typically in the same direction as the build-up direction. However with an increased overlap rate more of the heat transferred through the previously deposited track, which resulted in a gradual increase in the deviations of the dendritic growth from the build-up direction. It was shown that with lower overlap rate the as-deposited part had a higher dimensional precision and were therefore closer to the net shape of the finished part. Furthermore, the grain size fluctuation decreased with increased overlapping rate leading to a more uniform microstructure.

- L. Fengcheng et al. [24] investigated the influence of single direction raster (SDRS) and cross direction raster scanning (CDRS) as shown in Figure 7. Their result suggests that CDRS inhibits the columnar dendrite growth in the deposition direction which is 
characteristic for the SDRS. Furthermore, CDRS proved to have similar tensile strength and better ductility than the SDRS samples, which was attributed to a more uniform distribution of grain sizes after heat treatment in CDRS.
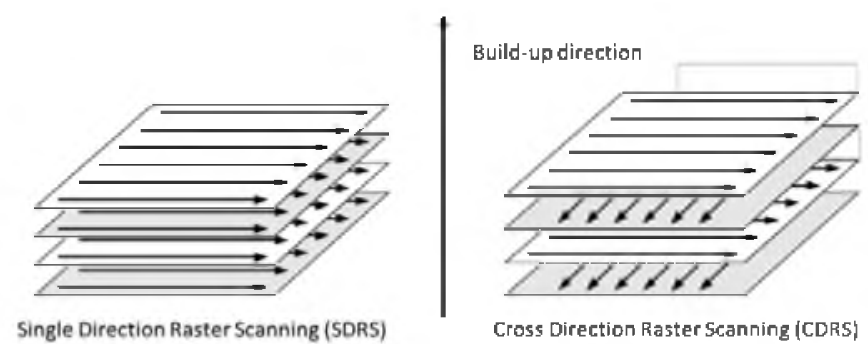

Figure 7. Single Direction Raster Scanning (SDRS) path and Cross Direction Raster Scanning (CDRS) path. Modified from [24].

- Awasthi et al. 2012 [48] studied the effect of specific energy input (laser power to powder feeding ratio) on the microstructure of a deposited nickel-based superalloy with composition close to Tribaloy T-700. Stainless steel $316 \mathrm{~L}$ was used as the substrate material in this study. Three sets of specific energy input where studied, $17.14 \mathrm{~kJ} / \mathrm{g}, 27.8$ $\mathrm{kJ} / \mathrm{g}$ and $32.25 \mathrm{~kJ} / \mathrm{g}$. In all of the samples, intermetallic (tcp) Lave phases where found which were attributed to the excess (above the solubility limit of the matrix phase) of silicon and molybdenum. Their study showed that the lower energy input rendered a higher microhardness in the deposit. This was explained by the difference in microstructure, the amount of dilution from the substrate to the deposit and the morphology of the different phases. Additionally a larger volume fraction of Lave phase particles where obtained using a lower specific energy input.

- J. Chen et al. [12] compared solution heat treated (SHT) cast Alloy 738 with deposited Alloy-738 samples. It was found that, due to the rapid cooling, $\gamma^{\prime}$ particles didn't precipitate from the $\gamma$ matrix in the as-deposited sample. The as deposited samples therefore had a supersaturated $\gamma$ solid solution structure. A standard heat treatment was applied to the deposited samples during which precipitation of $\gamma^{\prime}$ occurred and an increase of the tensile strength of the samples from $1202 \mathrm{MPa}$ to $1269 \mathrm{MPa}$ in the buildup direction was accomplished. In addition, there was an increase in hardness from $\mathrm{HV}$ 354 to HV 413. However, in comparison with SHT cast Alloy-738, deposited Alloy-738 had a lower volume fraction of fine $\gamma^{\prime}$ particles (24 vol.\% vs. 33 vol. \%). After SHT the $\gamma^{\prime}$ had a bimodal structure in both the deposited and cast sample, with coarse and fine $\gamma^{\prime}$ particles in the microstructure. However, the size of the bimodal $\gamma^{\prime}$ was generally finer for the deposited component compared to the cast component. In the deposited sample the coarse and fine particles sizes where approximately $0.35 \mu \mathrm{m}$ and $0.08 \mu \mathrm{m}$, respectively whereas the cast sizes for the coarse and fine particles where $0.75 \mu \mathrm{m}$ and $0.14 \mu \mathrm{m}$, respectively.

- J. Li et al. [37] investigated the effect of solution heat treatment on laser deposited Rene' 41 at $1065^{\circ} \mathrm{C}$ for $4 \mathrm{~h}$ and air quenching followed by age heat treatment at $760{ }^{\circ} \mathrm{C}$ for $16 \mathrm{~h}$ and air cooling. The as-deposited Rene' 41 consisted of fine directionally solidified grains with the presence of $\mathrm{Ti}$ and Mo enriched MC carbide particles which were distributed in the interdendritic areas. The size of the $\gamma^{\prime}$ in the dendritic core was larger than in the interdendritic areas, which was argued to result from large super saturation and fine-segregation of elements in the laser melting deposition manufacturing 
process. In order to dissolve the coarse $\gamma^{\prime}$ precipitates, and $\mathrm{MC}$ carbides, a solution heat treatment was applied. However, the solution heat treatment proved to be insufficient to dissolve the $\gamma^{\prime}$ particles, MC carbides and ultrafine re-precipitated $\gamma^{\prime}$ particles. An aging heat treatment was applied to the solution treated alloy as described earlier. After the aging the microstructure consisted of elongated $\gamma^{\prime}$ particles and interdendritic phases with lengths of 300-600 nm which mainly consisted of $\mathrm{M}_{23} \mathrm{C}_{6}$ particles, were the $\mathrm{M}$ represent $\mathrm{Mo}$ and $\mathrm{Cr}$. If the Mo content is high $\mathrm{M}_{6} \mathrm{C}$ were prone to form, replacing the $\mathrm{M}_{23} \mathrm{C}_{6}$. The precipitation of the $\gamma^{\prime}$ particles resulted in high hardness and ductility. However, the subsequent orientation and coalescence of the $\gamma^{\prime}$ precipitates resulted in decreased strength which suggest that the thermal history of the LMD alloy may cause problem when a standard heat treatment is introduced.

\section{Residual stresses}

Residual stresses can appear in materials which are subjected to plastic deformations, heat treatments, phase transformations or machining [49]

The raster direction has shown to have some effect, although not predominant, on the residual stress in the deposit [11], although A.H. Nickel et al. showed that the deflection of the substrate was significantly changed depending on raster direction. It was shown that on a beam substrate a lower deflection is expected by choosing a raster direction 90 degrees to the long axis of the substrate. The reasoning behind this phenomena is that large residual stresses are found in the transverse plane along the same axis as the deposition direction. This leads to the largest residual stresses acting along the short axis of the beam substrate which in turn leads to lower deflections of the substrate plate. Additionally it was argued that the largest residual stresses are found in the last re-melted track and by decreasing the length of the track a lower residual stress is obtained. This meant in the case of a square substrate that it was preferable to choose a spiral raster pattern which starts at the outer edges and spiral inwards.

The largest amount of compressive residual stress in LMD has been claimed to appear in the same direction as the vertical building direction. This was applicable to thin wall structures, rectangular structures and square pillars. These compressive stresses were present in the core of the structures while tensile stresses counter balanced them at the outer edges of the samples [11]. However, contrarily to Rangaswamy et al. [11], Moat et al. [10] additionally found large tensile residual stresses in the transverse direction along the building direction. These were present at the center top of the build-up. Moving down from top to bottom the tensile transverse residual stresses in the longitudinal direction went from approximately $420 \mathrm{MPa}$ to $0 \mathrm{MPa}$ while the compressive residual stresses in the vertical build-up direction increased from approximately 0 $\mathrm{MPa}$ to $410 \mathrm{MPa}$. These measurements where done on deposited Waspaloy on an Alloy-718 substrate [10].

\section{Surface finish}

The structure of the powder flow underneath the nozzle in LMD is an important factor in order to control the quality, size, accuracy and efficiency of the deposit [7]. Powder characteristics, nozzle embodiment and gas flow needs to be optimized in order to obtain a uniform and concentrated powder spot [50]. G. Zhu et al. [51] investigated the influence of the distance between the surface and the powder, and laser focus, respectively. They found that having the powder convergence point slightly below the substrate surface together with focusing the laser slightly above the surface yielded positive results in surface quality due to a self-regulated mechanism. However this comes at the cost of powder efficiency. The self-regulated mechanism was explained in the following way: 
Maximum deposit efficiency is reached when powder focus is leveled with the deposition surface and substrate surface is at the same height. When the powder focus moves from below substrate level to above substrate level the building height will firstly increase until it reaches a maximum at substrate level, and then gradually decrease when it moves above the substrate surface, see Figure 8 . This will cause an increase in building height when a negative deviation (a concave valley) of the surface is reached and a decrease in building height when a positive deviation (a convex top) of the surface is reached. This is attributed to the varying amount of powder concentrated in the laser affected area at the different positions, see Figure 9. Additionally, the laser focus has the same affect although contrary to the powder, the laser focus should be slightly above the surface of the deposit. The powder efficiency is then lowered when the laser focus is at the surface level and increases again when it moves below the surface. However, when the laser focus moves too far away from the surface of the deposit the powder efficiency will start to lower again [51].

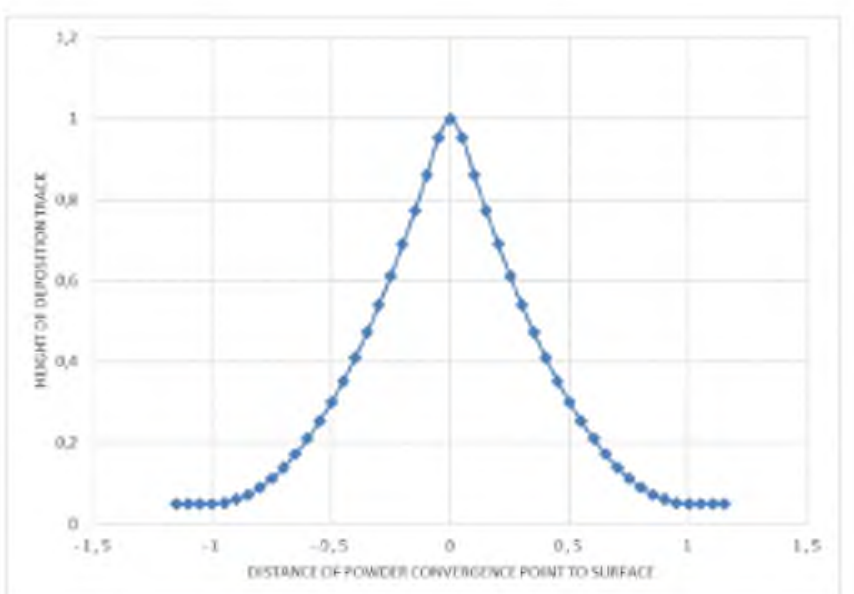

Figure 8. Maximum powder efficiency is achieved when the powder focus and the deposition surfaces meet and the distance between them are zero. When the powder focus moves below or above the surface a lower deposition efficiency is achieved which will decrease with the increase in distance. Modified from [51]

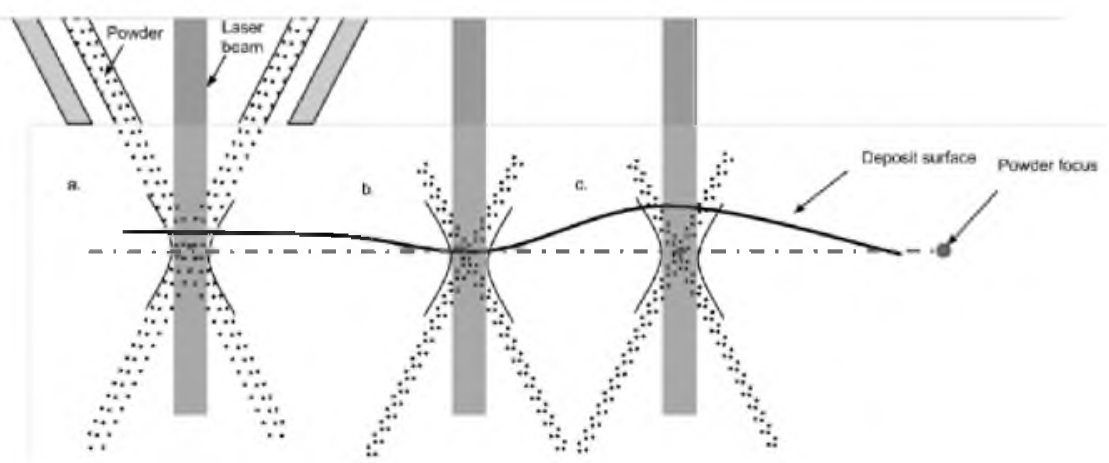

Figure 9. Illustration of the effect of the powder defocusing phenomenon. The nozzle has a constant height during the deposition of a layer with the mean powder focus position slightly below the surface of the deposit shown in (a.). This results in an average powder efficiency. In (b.) the surface of the deposit has dipped down and created a concave geometry which brings the powder focus closer to the surface of the deposit and thus increases the powder efficiency. In (c.) a convex top has been built up which brings the powder focus further away from the surface which results in a low powder efficiency. 


\section{Powder characteristics}

The powder characteristics have proved to have a large impact on the performance and characteristics of the deposited material. Surface morphology, size distribution, porosities, inclusions and satellite content are important factors which contribute to the performance and characteristics of the deposited material.

The interaction between powder and the laser largely depends on the particle size of the powder. It has been shown that larger particles decrease the laser which leads to more laser power being available at the substrate level. Consequently, the weld pool becomes wider and deeper with larger particles. Meanwhile smaller particles heat up more quickly and thus have a higher probability of being completely molten when entering the melt pool leading to less particle inclusions. However, the risk of overheating the powder increases.

Gas atomized (GA) powder is one of the most common powder types used in AM due to a wellestablished production method, high production rate and spherical morphology. However, GA has an inherent weakness of encapsulating gases during the solidification in the production process. The encapsulated gases are released when the powder is re-melted during the deposition but because of the rapid cooling in LMD the gas inclusions are trapped inside the deposited material. Additionally, GA has some problem with formation of satellites. The satellites in this case take the form of very small spherical particles which are sintered together with the desired spherical powder; as shown in Figure 10 (a.) [52].

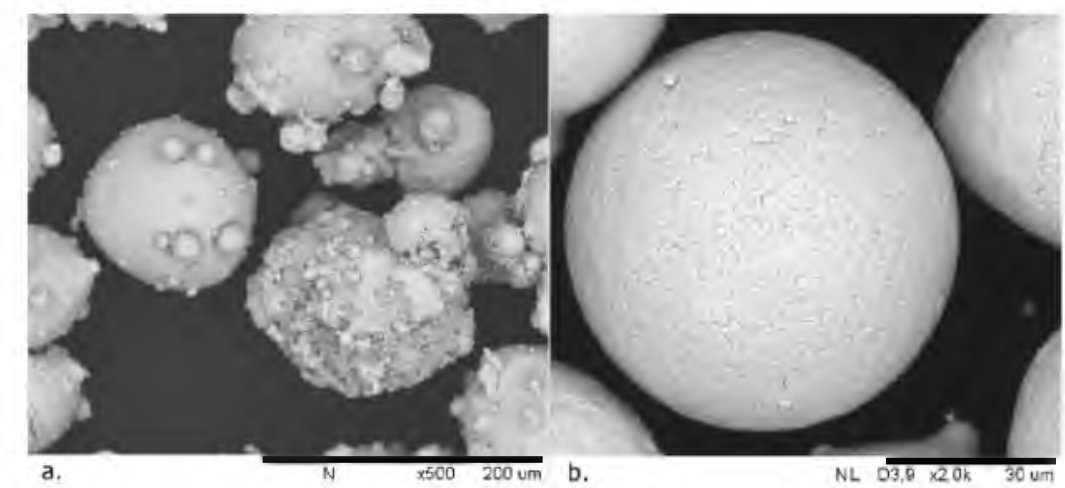

Figure 10 (a.) Gas Atomized Inconel 718 powder, with large amounts of satellites and uneven particle morphology. (b.) Plasma Rotary Electron Powder has a more spherical shape with less porosities and less satellites.

Plasma Rotation Electrode Process (PREP) powder is becoming more common in recent LMD literature. In comparison with GA powder PREP has finer spherical morphology, and low satellite content, and generally less irregularities as can be seen in Figure 10 (b.) [52]. Additionally, PREP powder has a lower internal porosity than GA powders.

Experiments conducted by Qi, et al. [27] showed that the porosity was up to 25 times less for deposited PREP powder in comparison with GA powder which had $0.03 \%$ and $0.76 \%$ porosities in the deposit respectively. When comparing Ti-6Al-4V PREP powder to GA powder, PREP powder had three times less porosity than the GA powder, this was concluded using MicroCT analysis [52]. X. Zhao et al. [31] has reported superior mechanical properties for deposited and heat treated PREP powder, with high temperature rupture life up to 20 times longer than that for GA powder. The superiority of the PREP powder was attributed to the relative low porosity in the PREP powder in comparison with the GA powder. GA powder creates gas inclusions and micro cracks in the deposits which are instigators of failure. 


\section{Discussion}

The relationship between the LMD process parameters and material characteristics is highly complex. For instance, process parameters such as laser power, powder feeding rate and traverse speed all affect the melt pool characteristics which in turn determine porosity, microstructure, bounding between layers and, dilution. A large number of reports about defect free superalloy samples being deposited have been published. However, process parameters optimized to avoid heat build-up for one geometry may not be suitable for a different geometry. The heat build-up causes the melt pool temperature to increase which in turn leads to lower deposit tracks, wider melt pools and more dilution. The effect of heat build-up in LMD is described by Zhang et al., [20]. It is therefore important, in order for LMD to be a reliable manufacturing method to control the heat build-up. This is either done by numerical analyses or online process control by temperature measurements. In order to reduce the heat build-up, a waiting time between deposit tracks/layers may be necessary. The waiting time affects the time-temperature curve of the deposition which consequently affect the microstructure of the material. One important parameter which may be crucial in this case is the ductility recovery temperature i.e. a measurement of the temperature when the material has recovered $5 \%$ of its ductility upon cooling after welding [53]. With a longer waiting time between deposition tracks/layers the deposit will have a lower temperature which leads to a shorter cooling time for the subsequent deposition tracks/layers. With sufficient cooling the material may dwell in the brittle temperature range for a shorter period of time and thereby lowering its susceptibility to cracking. The effect of the waiting time will be more predominant with a higher build-up since the chilling effect of the base material will lessen.

An additional result of the lowered cooling rate is that the surface of the deposit has large tensile residual stresses, contrary to the effect of a heat treated material where compressive residual stresses are expected at the surface. The distribution of residual stresses as described by Moat et al. [10] where large residual tensile stresses are located at the surface of the deposit is reducing the mechanical properties of the as-deposited samples. This in may suggest that a solution heat treatment with a subsequent aging treatment is necessary in order to relax the samples and attain satisfactory mechanical properties. In order to reduce this effect a water cooled substrate could be used which would also be beneficial for the columnar dendrite growth in the build-up direction as shown by Gäumann et al., [34]. Further Liu et al. [26], argued that the residual stresses in the overlap of two adjacent deposit tracks are higher in the re-melted overlap than in the middle of the deposit track. The middle of the deposit which isn't re-melted are tempered by the subsequent deposit, this has an annealing effect on the material which relaxes some of the stresses. This is claimed to lead to an uneven distribution of grain sizes.

The powder characteristics are an important factor and low quality powders can lead to porosity inside the deposit with degraded mechanical properties as a result. Characterization of powder batches should therefore be of best practice in order to prevent porosities from the powder to be encapsulated inside the deposit.

A low heat input can be achieved with LMD which makes it a preferable method for repairing sensitive components such as DS and SX blades and, cast components which are highly crack sensitive. The epitaxial grain growth in LMD is also beneficial for DS and SX blades. 


\section{Summary}

In order to better understand what recent research in laser metal deposition has contributed to the understanding of the laser metal deposition method, an effort of putting the collected knowledge in a summarized review has been attempted in this paper. The main objective has been to review the impact in which the governing parameters affect the material characteristics.

Some of the most important process parameters in LMD are the laser power, laser spot diameter, traverse speed and the powder feeding rate. These parameters affects the specific energy and the line mass which contributes to numerous effects in the LMD process including heat cycling, peak temperature, cooling time, dilution, porosities, cracks, surface finish, phase transformations, solidification mode and more. The ratio between the width and the height of a single deposit track is an important design factor from which the process parameters quickly can be assessed. A too high aspect ratio is obtained when a high heat input is used and can lead to dilution, cracking and poor forming precision. A too low aspect ratio is a sign of to low heat input which may lead to porosities and lack of fusion.

Changing raster direction from single direction raster scanning to cross direction raster scanning can break the columnar grain growth leading to more equiaxed grains. The deposits produced with cross directional raster scanning showed a tendency to higher ductility and similar yield strength to those produced by single direction raster scanning.

The powder quality has shown to be an important parameter where GA powder with irregular surface morphologies, internal porosities and high satellite content produced deposits with poor mechanical properties and 25 times more porosities in the deposit compared to PREP powder.

\section{Acknowledgements}

We thank Professor Olanrewaju Ojo and Dr. Krutika Vishwakarma at University of Manitoba in Canada for reviewing the paper.

\section{References}

1. Y. Yan, et al., "Rapid Prototyping and Manufacturing Technology: Principle, Representative Technics, Applications, and Development Trends," Tsinghua Science \& Technology, 14 (2009), $1-12$.

2. Q. Jia and D. Gu, "Selective laser melting additive manufacturing of Inconel 718 superalloy parts: Densification, microstructure and properties," Journal of Alloys and Compounds, 585 (2014), 713-721.

3. O. L. A. Harrysson, et al., "Direct metal fabrication of titanium implants with tailored materials and mechanical properties using electron beam melting technology, "Materials Science and Engineering: C, 28 (2008), 366-373.

4. L. Costa and R. Vilar, "Laser powder deposition," Rapid Prototyping Journal, 15 (2009), 264279.

5. Scopus.com, (2014). Analyze Results - Additive Manufacturing. Available at: http://www.scopus.com' [Accessed: 2014-06-05]

6. C. Hong, et al., "Laser metal deposition of TiC/Inconel 718 composites with tailored interfacial microstructures," Optics \& Laser Technology, 54 (2013), 98-109.

7. G. Zhu, et al., "Numerical simulation of metallic powder flow in a coaxial nozzle in laser direct metal deposition," Optics \& Laser Technology, 43 (2011), 106-113. 
8. J. Choi and Y. Chang, "Characteristics of laser aided direct metal/material deposition process for tool steel," International Journal of Machine Tools and Manufacture, 45 (2005), 597-607. 9. J. Mazumder, et al., "Closed loop direct metal deposition: art to part," Optics and Lasers in Engineering, 34 (2000), 397-414.

10. R. J. Moat, et al., "Residual stresses in laser direct metal deposited Waspaloy," Materials Science and Engineering: A, 528 (2011), 2288-2298.

11. P. Rangaswamy, et al., "Residual stresses in LENS® components using neutron diffraction and contour method," Materials Science and Engineering: A, 399 (2005), 72-83.

12. J. Chen and L. Xue, "Process-induced microstructural characteristics of laser consolidated IN-738 superalloy," Materials Science and Engineering: A, 527 (2010), 7318-7328.

13. C. P. Paul, et al., "Investigating laser rapid manufacturing for Inconel-625 components," Optics \& Laser Technology, 39 (2007), 800-805.

14. A. A. Antonysamy, "Microstructure, texture and mechanical property evolution during additive manufacturing of Ti6Al4V alloy for aerospace applications" (Ph.D. Thesis, University of Manchester, 2012), 1-315.

15. B. Geddes, H. Leon, and X. Huang, Superalloys : Alloying and Performance. Materials Park, OH, USA: ASM International, 2010.

16. J. Chen, S.-H. Wang, and L. Xue, "On the development of microstructures and residual stresses during laser cladding and post-heat treatments," Journal of Materials Science, 47 (2012), 779-792.

17. G. P. Dinda, A. K. Dasgupta, and J. Mazumder, "Laser aided direct metal deposition of Inconel 625 superalloy: Microstructural evolution and thermal stability," Materials Science and Engineering: A, 509 (2009), 98-104.

18. P. Ganesh, et al., "Fatigue and fracture toughness characteristics of laser rapid manufactured Inconel 625 structures," Materials Science and Engineering: A, 527 (2010), 7490-7497.

19. L. Thivillon, et al., "Potential of direct metal deposition technology for manufacturing thick functionally graded coatings and parts for reactors components," Journal of Nuclear Materials, 385 (2009), 236-241.

20. C. Zhang, L. Li, and A. Deceuster, "Thermomechanical analysis of multi-bead pulsed laser powder deposition of a nickel-based superalloy," Journal of Materials Processing Technology, 211 (2011), 1478-1487.

21. P. L. Blackwell, "The mechanical and microstructural characteristics of laser-deposited IN718," Journal of Materials Processing Technology, 170 (2005), 240-246.

22. J. Cao, et al., "Effect of overlap rate on recrystallization behaviors of Laser Solid Formed Inconel 718 superalloy," Optics \& Laser Technology, 45 (2013), 228-235.

23. C. Y. Kong, R. J. Scudamore, and J. Allen, "High-rate laser metal deposition of Inconel 718 component using low heat-input approach," Physics Procedia, 5, Part A (2010), 379-386.

24. F. Liu, et al., "The effect of laser scanning path on microstructures and mechanical properties of laser solid formed nickel-base superalloy Inconel 718," Journal of Alloys and Compounds, 509 (2011), 4505-4509.

25. F. Liu, et al., "Microstructural changes in a laser solid forming Inconel 718 superalloy thin wall in the deposition direction," Optics \& Laser Technology, 45 (2013), 330-335.

26. F. Liu, et al., "Microstructure and residual stress of laser rapid formed Inconel 718 nickelbase superalloy," Optics \& Laser Technology, 43 (2011), 208-213.

27. H. Qi, M. Azer, and A. Ritter, "Studies of Standard Heat Treatment Effects on Microstructure and Mechanical Properties of Laser Net Shape Manufactured INCONEL 718," Metallurgical and Materials Transactions A, 40 (2009), 2410-2422. 
28. I. Tabernero, et al., "Evaluation of the mechanical properties of Inconel 718 components built by laser cladding," International Journal of Machine Tools and Manufacture, 51 (2011), 465-470.

29. Q.-1. Zhang, J.-h. Yao, and J. Mazumder, "Laser Direct Metal Deposition Technology and Microstructure and Composition Segregation of Inconel 718 Superalloy," Journal of Iron and Steel Research, International, 18 (2011), 73-78.

30. Y. Zhang, et al., "Effect of Precipitation on the Microhardness Distribution of Diode Laser Epitaxially Deposited IN718 Alloy Coating," Journal of Materials Science \& Technology, 29 (2013), 349-352.

31. X. Zhao, et al., "Study on microstructure and mechanical properties of laser rapid forming Inconel 718," Materials Science and Engineering: A, 478 (2008), 119-124.

32. M. Zhong, et al., "Boundary liquation and interface cracking characterization in laser deposition of Inconel 738 on directionally solidified Ni-based superalloy," Scripta Materialia, 53 (2005), 159-164

33. S. Das, et al., "Direct laser fabrication of superalloy cermet abrasive turbine blade tips," Materials \& Design, 21 (2000), 63-73.

34. M. Gäumann, et al., "Single-crystal laser deposition of superalloys: processingmicrostructure maps," Acta Materialia, 49 (2001), 1051-1062.

35. M. Gäumann, et al., "Epitaxial laser metal forming: analysis of microstructure formation," Materials Science and Engineering: A, 271 (1999), 232-241.

36. J. Li and H. M. Wang, "Microstructure and mechanical properties of rapid directionally solidified Ni-base superalloy Rene' 41 by laser melting deposition manufacturing," Materials Science and Engineering: A, 527 (2010), 4823-4829.

37. J. Li, H. M. Wang, and H. B. Tang, "Effect of heat treatment on microstructure and mechanical properties of laser melting deposited Ni-base superalloy Rene'41," Materials Science and Engineering: A, 550 (2012), 97-102.

38. A. J. Pinkerton, et al., "Thermal and microstructural aspects of the laser direct metal deposition of waspaloy," Journal of Laser Applications, 18 (2006), 216-226.

39. L. Han, K. M. Phatak, and F. W. Liou, "Modeling of laser cladding with powder injection," Metallurgical and Materials Transactions B, 35 (2004), 1139-1150.

40. M. L. GRIFFITH, et al., Understanding the microstructure and properties of components fabricated by laser engineered net shaping (LENS), 2000.

41. A. J. Pinkerton and L. Li, "The significance of deposition point standoff variations in multiple-layer coaxial laser cladding (coaxial cladding standoff effects)," International Journal of Machine Tools and Manufacture, 44 (2004), 573-584.

42. L. Peng, et al., "Direct laser fabrication of nickel alloy samples," International Journal of Machine Tools and Manufacture, 45 (2005), 1288-1294.

43. K. Shah, et al., "Parametric study of development of Inconel-steel functionally graded materials by laser direct metal deposition," Materials \& Design, 54 (2014), 531-538.

44. J. J. Beaman, et al., "Additive/subtractive manufacturing research and development in Europe," DTIC Document2004.

45. K. Zhang, W. Liu, and X. Shang, "Research on the processing experiments of laser metal deposition shaping," Optics \& Laser Technology, 39 (2007), 549-557.

46. H. Qi and Z. Liu, "Modeling of Crystal Orientations in Laser Powder Deposition of Single Crystal Material," Physics Procedia, 39 (2012), 903-912.

47. W. Liu and J. N. DuPont, "Effects of substrate crystallographic orientations on crystal growth and microstructure development in laser surface-melted superalloy single crystals. Mathematical 
modeling of single-crystal growth in a melt pool (Part II)," Acta Materialia, 53 (2005), 15451558.

48. R. Awasthi, et al., "Effect of Specific Energy Input on Microstructure and Mechanical Properties of Nickel-Base Intermetallic Alloy Deposited by Laser Cladding," Metallurgical and Materials Transactions A, 43 (2012), 4688-4702.

49. I. C. Noyan and J. B. Cohen, Residual stress: measurement by diffraction and interpretation: Springer, 1987.

50. N. Yang, "Concentration model based on movement model of powder flow in coaxial laser cladding," Optics \& Laser Technology, 41 (2009), 94-98.

51. G. Zhu, et al., "The influence of laser and powder defocusing characteristics on the surface quality in laser direct metal deposition," Optics \& Laser Technology, 44 (2012), 349-356.

52. M. N. Ahsan, et al., "A comparative study of laser direct metal deposition characteristics using gas and plasma-atomized $\mathrm{Ti}-6 \mathrm{Al}-4 \mathrm{~V}$ powders," Materials Science and Engineering: A, 528 (2011), 7648-7657.

53. J. Andersson, "Weldability of Precipitation Hardening Superalloys - Influence of Microstructure" (Ph.D. thesis, Chalmers University of Technology, 2011), 1-243. 